\title{
Genótipos de capim-elefante sob pastejo no período de seca na Zona da Mata de Pernambuco: fatores relacionados à eficiência de pastejo ${ }^{1}$
}

\section{Márcio Vieira da Cunha ${ }^{2}$, Mércia Virginia Ferreira dos Santos ${ }^{3}$, Mário de Andrade Lira 4 , Alexandre Carneiro Leão de Mello ${ }^{5}$, Erinaldo Viana de Freitas ${ }^{2}$, Valéria Xavier de Oliveira Apolinário6}

\author{
1 Parte da dissertação do primeiro autor. Trabalho realizado pelo Acordo IPA/UFRPE, com apoio do CNPq e da Promata. \\ 2 PDIZ da UFRPE e Pesquisador do IPA. \\ 3 UFRPE. Bolsista do CNPq. \\ 4 IPA. Bolsista do CNPq. \\ 5 UFRPE. \\ 6 Graduanda em Zootecnia - UFRPE.
}

RESUMO - O experimento foi realizado com o objetivo de avaliar fatores relacionados à eficiência de pastejo de cinco genótipos de Pennisetum sp. (CE 08 A.D., Venezuela, HV-241, Elefante B e Hexaplóide) no período seco do ano na Zona da Mata de Pernambuco. Os genótipos foram manejados sob lotação rotacionada (44 dias de descanso e quatro dias de pastejo) ao longo de dois ciclos de pastejo. Adotou-se delineamento experimental em blocos ao acaso, com parcelas subdivididas (os genótipos representaram as parcelas e os ciclos de pastejo, as subparcelas) e quatro repetições. As massas de lâmina foliar total, verde e senescente pré-pastejo foram analisadas em seis repetições. O acúmulo e a eficiência de pastejo de lâmina foliar verde foram avaliados em delineamento em blocos casualizados, com quatro repetições. Os genótipos CE 08 A.D. e Elefante B apresentaram maiores massas de lâmina foliar total (1.374 kg de MS/ha) e verde pré-pastejo ( $737 \mathrm{~kg}$ de MS/ha) e maior acúmulo (654 kg de MS/ha/44 dias) e eficiência de pastejo de lâmina foliar verde (80\%). No HV-241, a alta eficiência de pastejo (100\% do acúmulo lâmina foliar verde) esteve associada ao baixo acúmulo de lâmina foliar verde (155 kg de MS/ha/44 dias). A menor eficiência de pastejo foi observada no Hexaplóide (59\% do acúmulo de lâmina foliar verde), possivelmente em virtude das altas perdas sob pastejo ( $30 \%$ da massa de lâmina foliar total pré-pastejo). A massa de lâmina foliar verde diminuiu mais acentuadamente até o segundo dia de pastejo, enquanto as perdas de lâmina foliar total foram maiores no $2 \underline{\mathrm{o}}$ e $3 \underline{\mathrm{o}}$ dias de pastejo. Os genótipos CE 08 A.D. e Elefante B têm potencial para serem utilizados em sistemas de lotação rotacionada na Zona da Mata pernambucana.

Palavras-chave: acúmulo de folhas verdes, híbrido, massa de forragem, perdas de forragem

\section{Elephantgrass genotypes under grazing during the dry period in the Forest Zone of Pernambuco: factors related to grazing efficiency}

\footnotetext{
ABSTRACT - The experiment was carried out to evaluate factors related to the grazing efficiency of fivePennisetum sp. genotypes (CE 08 A.D., Venezuela, HV-241, Elephant B and Hexaplóide) during the dry period in the Forest Zone of Pernambuco. Genotypes were managed under rotational stocking (44 days of resting and four days of grazing period). It was used a split-plot arrangement in a complete randomized block design (genotypes represented the plots; grazing cycles, the subplots). Six replications were used to determine pre-grazing total leaf blade mass and green and senescent leaf blade mass. Four replications were used for leaf blade accumulation and grazing efficiency and, for these variables, it was used a complete randomized blocks design. The CE 08 A.D. and Elephant B presented greater pre-graze total leaf blade mass, green leaf blade, green leaf blade accumulation, and grazing efficiency, with averages of 1,374 kg DM/ha, $737 \mathrm{~kg} \mathrm{DM} / \mathrm{ha}$, $654 \mathrm{~kg} \mathrm{DM} / \mathrm{ha} / 44$ days and $80 \%$ of the green leaf blade accumulation, respectively. The highest grazing efficiency (100\% of the green leaf blade accumulation) occurred at the HV-241 pastures. This high grazing efficiency was associated to the low green leaf blade accumulation ( $155 \mathrm{~kg}$ of MS/ha/44 days). The lowest grazing efficiency was observed for the Hexaplóide (59\% of the green leaf blade accumulation), possibly due to high losses under grazing (30\% of the pre-grazing total leaf blade mass). The green leaf blade mass decreased mostly until the second grazing day, while the losses of total leaf blade were higher in the second and third grazing days. The genotypes CE 08 A.D. and Elephant B presented potential to be used under rotational stocking, in the Pernambuco Forest Zone.
}

Key Words: forage losses, forage mass, green leaves accumulation, hybrid 


\section{Introdução}

O capim-elefante (Pennisetum purpureum Schum.) é nativo de regiões da África Tropical e foi introduzido no Brasil por volta de 1920 , por meio de mudas provenientes de Cuba. Atualmente, consiste em uma das forrageiras mais difundidas em todo o país (Daher, 2002).

É crescente o interesse pelo capim-elefante para formação de pastagens, haja vista os bons resultados na produção animal quando utilizado sob pastejo (Deresz, 2001; Erbesdobler et al., 2002; Santos et al., 2005). Entretanto, o desenvolvimento da tecnologia de produção animal em pastagens de capim-elefante depende da geração e seleção de novos genótipos adaptados ao sistema de lotação rotacionada (Pereira et al., 1997). Neste sentido, tem-se utilizado seus cruzamentos com milheto (Pennisetum glaucum (L.) R. Br.) para formação de híbridos interespecíficos.

Na pastagem, a produção de tecido foliar nas gramíneas é um processo contínuo, regulado pelos fatores ambientais e pelas características do dossel. À medida que o tecido foliar se acumula na planta, está sujeito à senescência e à deposição no solo, o que irá constituir o mantilho (Lemaire \& Agnusdei, 2000). O objetivo no manejo de pastagens é otimizar o aproveitamento do tecido foliar produzido e acumulado, promovendo diminuição das perdas por senescência e aumento da eficiência de pastejo (Lemaire, 1997; Santos et al., 2004).

Na caracterização de genótipos sob pastejo, é importante a avaliação das perdas de forragem decorrentes do pastejo animal, considerando os reflexos negativos da eficiência de pastejo e da persistência das plantas na pastagem.

Com o objetivo de fornecer subsídios à seleção de materiais adaptados ao pastejo, foram avaliados os fatores relacionados à eficiência de pastejo em genótipos de Pennisetum sp. no período seco do ano na Zona da Mata de Pernambuco.

\section{Material e Métodos}

O experimento foi realizado na Estação Experimental da Empresa Pernambucana de Pesquisa Agropecuária (IPA), no município de Itambé, Zona da Mata Seca de Pernambuco. O município situa-se nas coordenadas geográficas 07²5'00"S e 35\%06'00"WGr, a $190 \mathrm{~m}$ de altitude, com precipitação média anual de $1.356 \mathrm{~mm}$ (SUDENE, 1990) e temperatura média anual de $25^{\circ} \mathrm{C}$ (Encarnação, 1980).

O período experimental compreendeu os meses de dezembro de 2004 a abril de 2005, período seco da região, com precipitação de $170 \mathrm{~mm}$.
Foram avaliados cinco genótipos de Pennisetum sp., três de capim-elefante (CE 08 A.D., Venezuela, Elefante B) e dois híbridos do capim-elefante com milheto (HV-241 e Hexaplóide). Esses genótipos foram selecionados das Fases I (Mello et al., 2002) e II (Freitas et al., 2004) do Programa de Melhoramento Genético do capim-elefante, realizado pelo IPA/UFRPE, segundo metodologia proposta por Valle \& Souza (1995).

$\mathrm{O}$ experimento foi realizado em uma área de 5 ha, dividida em 12 piquetes, subdivididos em cinco áreas de aproximadamente $833 \mathrm{~m}^{2}$. Cada subdivisão foi ocupada por um genótipo de Pennisetum sp. A pastagem foi implantada no início do segundo semestre de 2003. Por ocasião da implantação, o solo foi arado, gradeado e recebeu 1,0 t de calcário dolomítico/ha, conforme resultados da análise do solo $\left(\mathrm{pH}\right.$ (água) $=5,3 ; \mathrm{P}=3,83 \mathrm{ppm} ; \mathrm{K}^{+}=0,3 ; \mathrm{Ca}^{++}=$ 3,$\left.1 ; \mathrm{Mg}^{++}=1,5 ; \mathrm{e}^{+++}=0,3 \mathrm{cmol}_{\mathrm{c}} / \mathrm{dm}^{3}\right)$. No plantio, foram utilizadas frações de colmo e espaçamento de $1 \mathrm{~m}$ entre linhas.

Antes do início do período experimental, as pastagens apresentavam aproximadamente 100 dias de crescimento e 2,5 m de altura. Visando à quebra da dominância apical e à uniformização, as pastagens foram submetidas a um pastejo durante 15 dias. Após a rebrotação, um ciclo de pastejo de 48 dias (44 dias de descanso e quatro dias de ocupação) antecedeu o início do experimento.

No período experimental, a pastagem foi manejada com ciclo de pastejo de 48 dias (44 dias de descanso e quatro dias de ocupação) utilizando-se vacas mestiças Holandês x Zebu, com peso vivo médio de $470 \mathrm{~kg}$, em lotação de dois animais/ha para cada genótipo. Os animais recebiam suplementação (30 kg/animal da mistura canade-açúcar enriquecida com $1 \%$ de uréia + sulfato de amônio) no cocho, após a única ordenha pela manhã,e retornavam à pastagem às $14 \mathrm{~h}$.

As avaliações, realizadas alternadamente a cada dois piquetes, durante dois ciclos de pastejo, ocorreram antes da entrada (pré-pastejo) e após a saída dos animais no piquete (pós-pastejo), em dois piquetes consecutivos. No primeiro piquete, as avaliações da massa e das perdas de lâmina foliar foram realizadas diariamente durante o período de ocupação. Foram avaliadas as massas de lâmina foliar total, verde e senescente e a biomassa aérea pré e pós-pastejo, as perdas de biomassa aérea, o mantilho, o acúmulo e a eficiência de pastejo de lâmina foliar verde.

A massa de lâmina foliar total, constituída de lâmina foliar verde e senescente, pré e pós-pastejo, foi estimada pela colheita manual das lâminas foliares em três pontos amostrais representativos da variação na massa de lâmina foliar (maior, menor e massa de lâmina foliar média).Consi- 
derou-se em cada ponto uma área correspondente a $1 \mathrm{~m}^{2}$, delimitada por um quadrado de PVC. O material colhido foi separado em lâminas verdes e senescentes. Após a pesagem de cada componente, foi retirada uma amostra para determinação da MS em estufa a $55^{\circ} \mathrm{C}$. Em seguida, foram determinados, visualmente, 30 pontos amostrais de $1 \mathrm{~m}^{2}$ no piquete, conforme a variação estipulada na massa de lâmina foliar. A freqüência de cada ponto amostral, dentro dos 30 pontos, multiplicada pelo seu respectivo peso proporcionou a estimativa da massa de lâmina foliar em $30 \mathrm{~m}^{2}$ do piquete. A massa de lâmina foliar total, em $\mathrm{kg}$ de MS/ha, foi estimada considerando as proporções de lâminas foliares verde e senescente, com base na MS desses componentes.

Após a colheita manual da massa de lâmina foliar nos pontos amostrais, os colmos foram cortados rente ao solo. Desse modo, as biomassas aéreas pré e pós-pastejo nos genótipos de Pennisetum sp. corresponderam ao somatório massa total de lâminas foliares + colmos.

As perdas de biomassa (lâminas foliares e colmos) pelo pastejo foram estimadas por meio da retirada de todo o material vegetal sobre o solo em três pontos de $1 \mathrm{~m}^{2}$, na linha de plantio. Diariamente, foram coletadas em cada ponto as lâminas foliares e os colmos caídos sobre o solo ou presos à planta, porém danificados, sem condições de recuperação. O material coletado foi separado em lâmina foliar e colmo, sendo pesado e mantido em estufa para determinação da $\mathrm{MS}$ a $55^{\circ} \mathrm{C}$. As perdas de biomassa pelo pastejo (perdas total, de lâmina foliar, e colmo) foram expressas em porcentagem da biomassa aérea pré-pastejo e em porcentagem da massa de lâmina foliar pré-pastejo, para a qual foram consideradas apenas as perdas de lâmina foliar.

$\mathrm{Na}$ avaliação do mantilho em cada genótipo de Pennisetum sp., foi realizada após o período de ocupação do piquete a colheita de todo o material vegetal sobre o solo no interior de um quadrado de PVC (1 m de lado), lançado duas vezes, aleatoriamente, na área de cada genótipo. Em seguida, o material coletado foi pesado e amostrado para determinação da $\mathrm{MS}$ em estufa a $55^{\circ} \mathrm{C}$.

$\mathrm{O}$ acúmulo de lâmina foliar verde ( $\mathrm{kg}$ de MS/ha/44 dias) foi calculado considerando a diferença entre a massa de lâmina foliar verde pré-pastejo do segundo ciclo de pastejo e a massa de lâmina foliar verde pós-pastejo do primeiro ciclo.

A eficiência de pastejo, em porcentagem da massa de lâmina foliar verde acumulada, foi obtida pela fórmula (Adaptada de Stuth et al., 1981):

Eficiência de pastejo $=\frac{\text { MLVPRE }-(\text { MLVPOS }+P)}{\text { acúmulo de lâmina foliar verde }} \times 100$

em que MLVPRE = massa de lâmina foliar verde pré-pastejo (kg de MS/ha); MLVPOS = massa de lâmina foliar verde póspastejo (kg de MS/ha); e $\mathrm{P}=$ perdas de lâmina foliar pela ação do pastejo (kg de MS/ha).

Utilizou-se delineamento experimental em blocos ao acaso com parcelas subdivididas e quatro repetições (blo$\cos$ ), à exceção das massas de lâmina foliar total, verde e senescente, nas quais foram utilizadas seis repetições. Os genótipos de Pennisetum sp. corresponderam às parcelas e os dois ciclos de pastejo, às subparcelas. Apenas para o acúmulo e a eficiência de pastejo das lâminas foliares verdes, foi utilizado delineamento em blocos casualizados com quatro repetições. Os piquetes representaram os blocos experimentais, em razão da heterogeneidade do terreno (inclinação e características químicas do solo).

As análises estatísticas foram realizadas utilizando-se o pacote estatístico SAS (SAS, 1999). A normalidade dos dados foi testada pelo procedimento UNIVARIATE do SAS e a homogeneidade da variância, pelo teste de Bartlett. Quando esses pré-requisitos da análise de variância não foram atendidos, os dados foram transformados. Para realização da análise de variância, foi utilizado o procedimento GLM (General Linear Models) do SAS. As médias entre genótipos foram comparadas pelo teste Tukey, a 5 ou $10 \%$ de significância, conforme a significância do teste $F$ na análise de variância. As médias entre ciclos de pastejo foram comparadas pelo teste $\mathrm{F}$, considerando 5 ou $10 \%$ de significância.

As análises de regressão da massa de lâmina foliar verde e das perdas de lâmina foliar em função do dia de pastejo foram realizadas utilizando-se o software SigmaPlot para Windows, versão 9.01.

\section{Resultados e Discussão}

A massa de lâmina foliar total pré-pastejo diferiu $(\mathrm{P}=0,0255)$ entre os genótipos de Pennisetum sp (o CE 08 A.D. e o Elefante B foram superiores ao HV-241 e ao Hexaplóide), enquanto a massa de lâmina foliar pré-pastejo do Venezuela não diferiu da obtida nos demais genótipos (Tabela 1).

As diferenças na massa de lâmina foliar total prépastejo podem ser atribuídas à massa de lâmina foliar verde, que foi diferente $(\mathrm{P}<0,0001)$ entre os genótipos. A massa de lâmina foliar senescente, no entanto, não diferiu $(\mathrm{P}=0,7355)$ e apresentou média de $612 \mathrm{~kg} / \mathrm{ha}$ de MS. Quanto à massa de lâmina foliar verde pré-pastejo, o Elefante B e o CE 08 A.D. foram superiores ao Venezuela, ao Hexaplóide e ao HV-241, cuja massa foi a menor.

Os genótipos Elefante B e CE 08 A.D. apresentaram, em média, $1.374 \mathrm{~kg}$ de MS/ha de massa de lâmina foliar total. 
Tabela 1 - Massas de lâmina foliar total, verde, e senescente pré-pastejo (kg de MS/ha) em genótipos de Pennisetum sp. Table 1 - Pre-grazing total leaf blade mass, green leaf blade mass, and senescent leaf blade mass (kg DM/ha) in Pennisetum sp. genotypes

Massa de lâmina foliar total

Total leaf blade mass
Massa de lâmina foliar verde Green leaf blade mass
Massa de lâmina foliar senescente Senescent leaf blade mass

Genótipo

Genotype

\begin{tabular}{lrll}
\hline CE 08 A.D. & $1.375 \mathrm{a}$ & $771 \mathrm{a}$ & $604 \mathrm{a}$ \\
Venezuela & $1.112 \mathrm{ab}$ & $468 \mathrm{~b}$ & $644 \mathrm{a}$ \\
HV-241 & $857 \mathrm{~b}$ & $661 \mathrm{a}$ & $196 \mathrm{c}$ \\
Elefante B & $1.374 \mathrm{a}$ & $704 \mathrm{a}$ & $670 \mathrm{a}$ \\
Hexaplóide & $933 \mathrm{~b}$ & $453 \mathrm{~b}$ & $480 \mathrm{a}$ \\
\hline
\end{tabular}

Ciclos de pastejo

Grazing cycles

\begin{tabular}{|c|c|c|c|}
\hline $1 \underline{\mathrm{o}}$ & $1.256 \mathrm{~A}$ & $450 \mathrm{~B}$ & $806 \mathrm{~A}$ \\
\hline $2 \underline{\underline{O}}$ & $1.004 \mathrm{~B}$ & $587 \mathrm{~A}$ & 417B \\
\hline Média (Mean) & 1.130 & 518 & 612 \\
\hline $\mathrm{CV}_{\text {genótipo, }} \%\left(C V_{\text {genotype }} \%\right)$ & 40 & 21 & 34 \\
\hline$C V_{\text {ciclo de pastejo, }} \%\left(C V_{\text {grazing cycle }}, \%\right)$ & 15 & 30 & 30 \\
\hline
\end{tabular}

Médias seguidas de letras minúsculas diferentes na coluna, em genótipos, diferem $(\mathrm{P}<0,05)$ pelo teste Tukey.

Médias seguidas de letras maiúsculas diferentes na coluna, em ciclos de pastejo, diferem $(P<0,05)$ pelo teste $F$.

Means followed by different lower case letters in the column, within genotypes, differ $(P<0.05)$ by Tukey test.

Means followed by different upper case letters in the column, within grazing cycles, differ $(P<0.05)$ by $F$ test.

Lima et al. (2004), em estudo com capim-elefante manejado sob lotação rotacionada (período de ocupação de dois dias e de descanso, de 40 dias), verificaram média de $1.713 \mathrm{~kg}$ de MS/ha de massa de lâmina foliar total para o cv. Guaçu no período seco do ano. Restle et al. (2002), utilizando capimelefante sob lotação contínua, verificaram massa de lâmina foliar de $1.160 \mathrm{~kg}$ de MS/ha para o cv. Taiwan A-146, também no período seco do ano.

No período seco do ano, Neumann et al. (2005), em pastagem de capim-elefante manejada sob lotação contínua, verificaram massa de lâmina foliar verde pré-pastejo de $800 \mathrm{~kg}$ de MS/ha. Apesar de a média dos genótipos de Pennisetum sp. ter sido menor, os genótipos CE 08 A.D. e Elefante B apresentaram médias próximas à relatada por esses autores.

A oferta de lâmina foliar total nos genótipos de Pennisetum sp. variou de 14 a 9 kg de MS de lâmina foliar/ vaca/dia (correspondente a 3 e $2 \%$ do PV, respectivamente), considerando o peso vivo médio das vacas, equivalente a $470 \mathrm{~kg}$.Segundo Mott (1984), quando a oferta de forragem é inferior a $5 \%$ do PV, o consumo de MS pelo animal pode ser afetado. Oferta de lâmina foliar menor (representando $1 \%$ do PV) foi registrada por Aroeira et al. (1999) em pastagem de capim-elefante durante o período seco do ano.

As massas de lâmina foliar total e senescente prépastejo diminuíram $(\mathrm{P}=0,0091$ e $\mathrm{P}<0,0001$, respectivamente $)$ do primeiro para o segundo ciclo de pastejo, como resultado da intensa redução da massa de lâmina foliar senescente, provavelmente pelo pastejo animal e pela deiscência durante o período de descanso das pastagens. Possivelmente, houve estímulo para que a massa de lâmina foliar verde pré-pastejo fosse maior $(\mathrm{P}=0,0064)$ no segundo ciclo de pastejo (Tabela 1). Parsons et al. (1988) afirmaram que, quando determinada proporção de lâmina foliar senescente é removida de um perfilho, ocorre durante a rebrota aumento na proporção de lâminas foliares verdes, de alta capacidade fotossintética.

Não houve efeito da interação genótipo $\times$ ciclo de pastejo sobre as massas de lâminas foliares total, verde e senescente pré-pastejo ( $\mathrm{P}=0,3963 ; 0,3247 ; 0,9797$, respectivamente). No pós-pastejo, as massas de lâminas foliares total e senescente não foram diferentes $(P=0,9151$ e 0,9156, respectivamente) entre os genótipos de Pennisetum sp.e apresentaram valores médios de 458 e $422 \mathrm{~kg}$ de MS/ha, respectivamente (Tabela 2). A massa de lâmina foliar senescente correspondeu a $92 \%$ da massa total de lâmina foliar pós-pastejo, o que representa incremento de 32 pontos percentuais em relação ao pré-pastejo, indicando a preferência dos animais pelas lâminas verdes.

As massas de lâminas foliares total e senescente póspastejo foram menores $(\mathrm{P}=0,0012$ e 0,0007 , respectivamente) no segundo ciclo de pastejo (Tabela 2), o que pode estar relacionado às menores massas de lâminas foliares total e senescente pré-pastejo no segundo ciclo de pastejo. Não houve efeito da interação genótipo $\times$ ciclo de pastejo sobre estas variáveis $(\mathrm{P}=0,2129$ e 0,1486 , respectivamente). Verificou-se, no entanto, efeito significativo $(\mathrm{P}=0,0007)$ dessa interação sobre a massa de lâmina foliar verde pós- 
Tabela 2 - Massas de lâmina foliar total e senescente pós-pastejo (kg de MS/ha) em genótipos de Pennisetum sp. Table 2 - Post-grazing total and senescent leaf blade mass (kg DM/ha) in Pennisetum sp. genotypes

\begin{tabular}{lcc}
\hline & $\begin{array}{c}\text { Massa de lâmina foliar total } \\
\text { Total leaf blade mass }\end{array}$ & $\begin{array}{c}\text { Massa de lâmina foliar senescente } \\
\text { Senescent leaf blade mass }\end{array}$ \\
\hline Genótipo & & \\
Genotype & & 466 \\
\hline CE 08 A.D. & 507 & 413 \\
Venezuela & 425 & 412 \\
HV-241 & 424 & 379 \\
Elefante B & 473 & 442 \\
Hexaplóide & 462 & \\
\hline Ciclos de pastejo & & \\
Grazing cycles & & \\
\hline o & $537 \mathrm{~A}$ & $311 \mathrm{~A}$ \\
20 & $379 \mathrm{~B}$ & $334 \mathrm{~B}$ \\
Média (Mean) & 458 & 422 \\
CVgenótipo, (CVgenotype, \%) & 45 & 46 \\
CVciclo de pastejo, \% (CVgrazing cycle, \%) & 28 & 31 \\
\hline
\end{tabular}

Médias seguidas de letras maiúsculas diferentes na coluna, em ciclos de pastejo, diferem $(P<0,05$ para massa de folhas senescentes; $P<0,10$ para massa de forragem) pelo teste $F$.

Means followed by different upper case letters in the column, within grazing cycles, differ $(P<0.05$, for senescent leaf blade mass; $P<0.10$, for total leaf blade mass) by $F$ test.

pastejo. Neste sentido, apenas no genótipo Elefante B, a quantidade de lâminas verdes aumentou do primeiro para o segundo ciclo de pastejo (Figura 1), possivelmente em decorrência da maior quantidade de perfilhos aéreos novos neste genótipo (Cunha, 2006).

A massa de lâmina foliar verde diminuiu de forma exponencial durante o período de ocupação do piquete (Figura 2). Essa redução na massa de lâmina foliar verde foi mais expressiva nos dois primeiros dias de pastejo.

Segundo Sollenberger et al. (2005), a afirmação de que a massa de forragem declina a taxas constantes durante o período de ocupação do piquete está quase sempre incorreta, pois não considera a incompleta utilização da pasta-

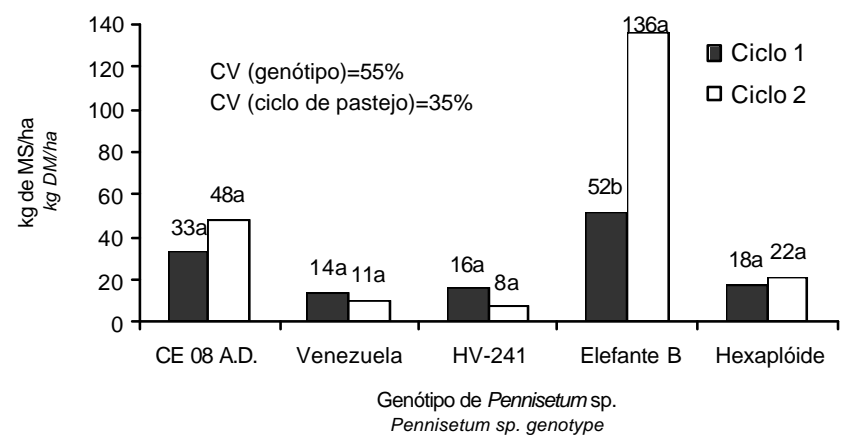

Figura 1 - Massa de lâmina foliar verde pós-pastejo em genótipos de Pennisetum $s p$.

Figure 1 - Post-grazing green leaf blade mass in Pennisetum sp. genotypes.

Médias dentro dos genótipos com letras diferentes diferem $(\mathrm{P}<0,05)$ pelo teste $\mathrm{F}$.

Genotypes means followed by different letters differ $(P<0.05)$ by $F$ test. gem e as mudanças estruturais no dossel durante o período de ocupação do piquete. Assim, é possível que, no período seco do ano, o período de ocupação do piquete seja menor, resultando em dieta de melhor qualidade, que poderá refletir sobre a suplementação e a resposta animal.

Considerando que a massa de lâmina foliar total pré-pastejo foi diferente e que as massas de lâminas foliares pós-pastejo entre os genótipos foram próximas,é possível que haja um limite no qual as lâminas não sejam mais consumidas durante o período de ocupação da pastagem. Esse limite provavelmente seria imposto por áreas no perfil da pastagemque afetariam a acessibilidade da forragem em oferta. De acordo com Brâncio et al. (2003), à medida que os animais selecionam as partes mais palatáveis das plantas, (em geral as folhas verdes), a pastagem apresenta

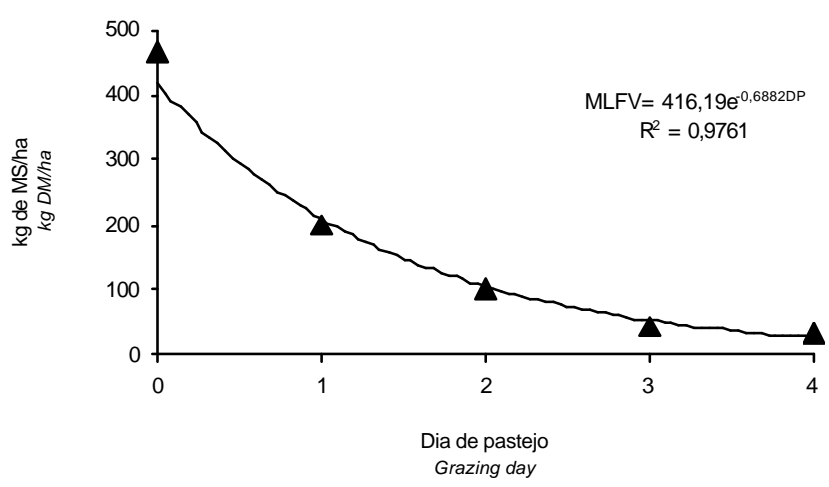

Figura 2 - Massa de lâmina foliar verde (MLFV) em função dos dias de pastejo (DP) em genótipos de Pennisetumsp.

Figure 2 - Green leaf blade mass as a function of the grazing day, in Pennisetum sp. genotypes. 
proporção crescente de material não preferido ou recusado, como colmos e material morto, ao longo do período de ocupação, dificultando a seleção e a ingestão de forragem.

A biomassa aérea pré-pastejo diferiu entre os genótipos de Pennisetum sp. $(\mathrm{P}=0,0853)$. O genótipo HV-241 apresentou menor biomassa aérea em comparação ao CE 08 A.D., ao Venezuela e ao Elefante B. A biomassa aérea pré-pastejo do Hexaplóide não diferiu da obtida nos demais genótipos. No pós-pastejo, a biomassa aérea (média de $10.770 \mathrm{~kg}$ de $\mathrm{MS} / \mathrm{ha})$ não diferiu $(\mathrm{P}=0,1198)$ entre os genótipos de Pennisetum sp. (Tabela 3).

As biomassas aéreas pré e pós-pastejo diminuíram ( $\mathrm{P}=0,0007$ e 0,0026 , respectivamente) do primeiro para $\mathrm{o}$ segundo ciclo (Tabela 3 ). Os resultados sugerem que o dano promovido à touceira pelos animais, decorrente da quebra de colmos e da desfolhação, associado ao estresse ambiental do período de seca, são possíveis fatores para a redução da biomassa aérea dos genótipos de Pennisetum sp. entre os ciclos de pastejo.

A biomassa aérea pré-pastejo do segundo ciclo foi menor que a biomassa aérea pós-pastejo do primeiro ciclo, o que comprova a ocorrência de perdas de biomassa durante o período de descanso das pastagens de Pennisetum sp.

Tabela 3 - Biomassa aérea (kg de MS/ha) pré e pós-pastejo em genótipos de Pennisetum sp.

Table 3 - $\quad$ Pre-grazing and post-grazing herbage mass of Pennisetum sp. genotypes

\begin{tabular}{lcc}
\hline & $\begin{array}{c}\text { Pré-pastejo } \\
\text { Pre-grazing }\end{array}$ & $\begin{array}{c}\text { Pós-pastejo } \\
\text { Post-grazing }\end{array}$ \\
\hline Genótipo & & \\
Genotype & & \\
\hline CE 08 A.D. & $13.338 \mathrm{a}$ & $12.131 \mathrm{a}$ \\
Venezuela & $12.934 \mathrm{a}$ & $11.885 \mathrm{a}$ \\
HV-241 & $7.789 \mathrm{~b}$ & $7169 \mathrm{a}$ \\
Elefante B & $13.567 \mathrm{a}$ & $12.580 \mathrm{a}$ \\
Hexaplóide & $10.782 \mathrm{ab}$ & $10.085 \mathrm{a}$ \\
\hline Ciclos de pastejo & & \\
Grazing cycle & & \\
\hline o & $13.188 \mathrm{~A}$ & $9.546 \mathrm{~B}$ \\
2. & $10.176 \mathrm{~B}$ & 10.770 \\
Média & 11.682 & 39 \\
Mean & & \\
CVgenótipo, \% & 16 & \\
CVgenotype, $\%$ & & \\
CVciclo de pastejo, $\%$ & 19 & \\
CVgrazing cycle, $\%$ & & \\
\hline
\end{tabular}

Médias seguidas de letras minúsculas diferentes na coluna, em genótipos, diferem $(P<0,10)$ pelo teste Tukey.

Médias seguidas de letras maiúsculas diferentes na coluna, em ciclos de pastejo, diferem $(P<0,05)$ pelo teste $F$.

Means followed by different lower case letters in the column, within genotypes, differ $(P<0.10)$ by Tukey test.

Means followed by different upper case letters in the column, within grazing cycle, differ $(P<0.05)$ by $F$ test.
A biomassa aérea pré e pós-pastejo não foi influenciada ( $\mathrm{P}=0,4174$ e 0,4168) pela interação genótipo $\times$ ciclo de pastejo. Apesar de a biomassa aérea pré-pastejo não ter variado conforme o genótipo, as perdas relativas (ou seja, em porcentagem da biomassa aérea pré-pastejo) de biomassa pelo pastejo não diferiram $(\mathrm{P}=0,1627 ; 0,1302 \mathrm{e}$ 0,2211 para perdas total, de lâmina foliar, e colmo, respectivamente) entre os genótipos. Em média, essas perdas representaram apenas $5 \%$ da biomassa aérea, sendo $2 \%$ relativo às perdas de lâminas foliares e 3\% às perdas de colmos (Tabela 4).

As perdas total, de lâmina foliar e de colmo pelo pastejo foram menores ( $\mathrm{P}<0,0001 ; 0,0290$ e 0,0001, respectivamente) no segundo ciclo de pastejo (Tabela 4), provavelmente em razão da menor biomassa aérea nos genótipos de Pennisetum sp. As perdas de biomassa não foram influenciadas pela interação genótipo $\times$ ciclo de pastejo $(\mathrm{P}=0,2208 ; 0,1561$ e 0,1914, para perdas total, de lâmina foliar e de colmo, respectivamente).

As perdas de lâmina foliar pelo pastejo, em porcentagem da massa de lâmina foliar total pré-pastejo, diferiram $(\mathrm{P}=0,0421)$ entre os genótipos de Pennisetum sp. As perdas de lâmina foliar nos genótipos Venezuela e Hexaplóide foram maiores que as do HV-241, mas não diferiram das perdas do CE 08 A.D. e do Elefante B (Tabela 4).

Lopes et al. (2003) observaram perdas de lâmina foliar pela ação do pastejo de 20 a $18 \%$ da massa de lâmina foliar pré-pastejo em pastagem de capim-elefante. Neste estudo, as perdas de lâmina foliar nos genótipos Venezuela e Hexaplóide foram superiores (em média, de 31\%), entretanto, o HV-241 apresentou perdas menores que as observadas por esses autores. Ressalta-se que a intensidade na qual as perdas ocorrem depende das condições climáticas, do estádio de desenvolvimento e da arquitetura da planta, bem como da lotação animal e da massa de forragem na pastagem (Hillesheim, 1988).

Não houve efeito do ciclo de pastejo $(\mathrm{P}=0,7054)$, nem da interação genótipo $\times$ ciclo de pastejo $(P=0,9672)$, sobre as perdas de lâmina foliar em porcentagem da massa total de lâmina foliar pré-pastejo.

As perdas de lâmina foliar pelo pastejo, em porcentagem da massa de lâmina foliar total pré-pastejo, durante o período de ocupação do piquete tiveram comportamento quadrático (Figura 3); as perdas aumentaram até o segundo dia de pastejo e diminuíram do $3 \underline{\text { o }}$ para o 4 o dia de pastejo. Quadros et al. (2002) sugeriram que as perdas são mais elevadas no início do período de pastejo, quando a quantidade de MS verde é maior.

O intervalo de maior perda de lâmina foliar ocorreu após diminuição mais expressiva na quantidade de lâminas foliares 
Tabela 4 - Perdas relativas de biomassa aérea (\% da biomassa aérea pré-pastejo) e de lâmina foliar (\% da massa de lâmina foliar total pré-pastejo) pelo pastejo e mantilho (kg de MS/ha) em genótipos de Pennisetum sp.

Table 4 - Relative herbage mass losses (\% pre-grazing herbage mass) and leaf blade losses (\% pre-grazing total leaf blade mass) by grazing and litter ( $\mathrm{kg}$ DM/ha) of Pennisetum sp. genotypes

\begin{tabular}{|c|c|c|c|c|c|}
\hline \multirow[b]{2}{*}{$\begin{array}{l}\text { Genótipo } \\
\text { Genotype }\end{array}$} & \multicolumn{3}{|c|}{$\begin{array}{c}\text { Perda relativa } \\
\text { Relative loss }\end{array}$} & \multirow[t]{2}{*}{$\begin{array}{l}\text { Perda de lâmina foliar } \\
\text { Leaf blade loss }\end{array}$} & \multirow[t]{2}{*}{$\begin{array}{l}\text { Mantilho } \\
\text { Litter }\end{array}$} \\
\hline & $\begin{array}{c}\text { Total } \\
\text { Total } \\
\end{array}$ & $\begin{array}{l}\text { Lâmina foliar } \\
\text { Leaf blade }\end{array}$ & $\begin{array}{c}\text { Colmo } \\
\text { Stem }\end{array}$ & & \\
\hline CE 08 A.D. & 5,6 & 2,0 & 3,6 & $20 \mathrm{ab}$ & $4.903 \mathrm{ab}$ \\
\hline Venezuela & 5,9 & 2,7 & 3,2 & $31 \mathrm{a}$ & $6.303 a$ \\
\hline HV-241 & 3,6 & 1,7 & 1,9 & $14 \mathrm{~b}$ & $4.094 \mathrm{~b}$ \\
\hline Elefante B & 4,2 & 1,8 & 2,4 & $18 \mathrm{ab}$ & $3.947 b$ \\
\hline Hexaplóide & 5,7 & 2,2 & 3,5 & $30 \mathrm{a}$ & $4.125 b$ \\
\hline
\end{tabular}

Ciclo de pastejo

Grazing cycle

\begin{tabular}{|c|c|c|c|c|c|}
\hline $1^{\circ}$ & $6,4 \mathrm{~A}$ & $3,1 \mathrm{~A}$ & $3,4 \mathrm{~A}$ & $34 \mathrm{~A}$ & $4.122 \mathrm{~B}$ \\
\hline $2^{\circ}$ & $3,6 \mathrm{~B}$ & $1,1 \mathrm{~B}$ & $2,5 \mathrm{~B}$ & $12 \mathrm{~A}$ & $5.227 \mathrm{~A}$ \\
\hline Média & 5,0 & 2,1 & 2,9 & 23 & 4674 \\
\hline Mean & & & & & \\
\hline $\begin{array}{l}\text { CVgenótipo, } \% \\
\text { CVgenotype, } \%\end{array}$ & 46 & 36 & 31 & 19 & 14 \\
\hline $\begin{array}{l}\text { CVciclo de pastejo, \% } \\
\text { CVgrazing cycle, } \%\end{array}$ & 35 & 26 & 26 & 25 & 22 \\
\hline
\end{tabular}

Médias seguidas de letras minúsculas diferentes na coluna, em genótipos, diferem $(P<0,05)$ pelo teste Tukey.

Médias seguidas de letras maiúsculas diferentes na coluna, em ciclos de pastejo, diferem $(P<0,05)$ pelo teste $F$.

Means followed by different lower case letters in the column, within genotypes, differ $(P<0.05)$ by Tukey test.

Means followed by different upper case letters in the column, within grazing cycle, differ $(P<0.05)$ by $F$ test.

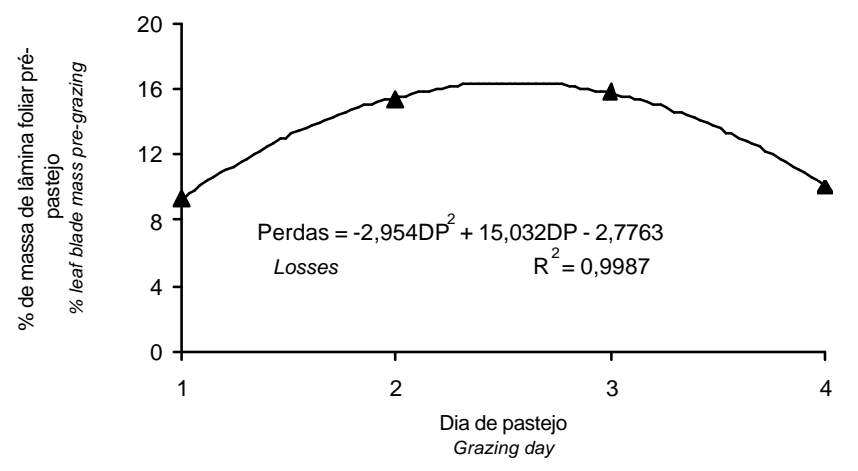

Figura 3 - Perdas de lâmina foliar durante o pastejo (DP) em genótipos de Pennisetum sp.

Figure 3 - Leaf blade losses as a function of the grazing day in Pennisetum sp. genotypes.

verdes (Figura 2), sugerindo que a procura do animal pelas lâminas foliares verdes à medida que este componente se tornava menos disponível contribuiu para aumentar as perdas de lâmina foliar.

O mantilho nos genótipos de Pennisetum sp. foi diferente $(\mathrm{P}=0,0020)$. $\mathrm{O}$ mantilho representa substrato para a fauna e os microrganismos do solo, tornando-se fonte importante de nutrientes, tanto em ecossistemas naturais quanto agrícolas, nos quais a interação crescimento da planta $\times$ decomposição do mantilho é essencial para fertilidade do solo (Dilly et al., 2004).
O mantilho foi maior no Venezuela, quando comparado ao HV-241, Elefante B e Hexaplóide, enquanto o CE 08 A.D. não diferiu dos demais genótipos (Tabela 4). Apesar de as perdas relativas não terem variado entre os genótipos, possivelmente contribuíram de modo diferenciado na formação do mantilho, considerando as perdas absolutas e a diferenças na biomassa aérea pré-pastejo entre os genótipos.

$\mathrm{O}$ mantilho foi maior $(\mathrm{P}=0,0326)$ no segundo ciclo de pastejo, no qual houve acúmulo de $1.105 \mathrm{~kg}$ de MS/ha em relação ao primeiro ciclo (Tabela 4), provavelmente em decorrência do tombamento e da quebra de plantas ou de partes da planta no processo de pastejo do animal e das perdas por senescência durante o período de descanso. $\mathrm{O}$ mantilho não foi influenciado $(\mathrm{P}=0,8574)$ pela interação genótipo $\times$ ciclo de pastejo.

Cecato et al. (2001) consideraram alta a produção de mantilho em pastagem de capim-tanzânia (Panicum maximumJacq.), ao verificarem produção média de $2.179 \mathrm{~kg}$ de MS/ha de mantilho. Embora a produção média de mantilho nos genótipos de Pennisetum sp. tenha sido maior que a observada por esses autores, esta produção é resultado do acúmulo das perdas de biomassa e de sua decomposição ao longo do tempo de utilização da pastagem.

$\mathrm{O}$ acúmulo de lâmina foliar verde diferiu $(\mathrm{P}=0,0115)$ entre os genótipos de Pennisetum sp. (Tabela 5). O CE 08 A.D. e Elefante B, em comparação ao HV-241, apresentaram 
maior acúmulo. O Venezuela e o Hexaplóide, no entanto, não diferiram dos demais genótipos.

A taxa de acúmulo de lâmina foliar variou de $15 \mathrm{a} 4 \mathrm{~kg}$ de MS/ha/dia. Paciullo et al. (2003) reportaram acúmulo de lâmina foliar em pastagem de capim-elefante de 126 a $9 \mathrm{~kg}$ de $\mathrm{MS} / \mathrm{ha} / \mathrm{dia}$, conforme a período do ano. Carvalho et al. (2001) estudaram o efeito do período do ano sobre a taxa de acúmulo de forragem em pastagens de Cynodon spp. e verificaram que os genótipos responderam de forma diferente nos períodos estudadas. Desse modo, a baixa taxa de acúmulo de lâminas foliares nos genótipos de Pennisetum sp. pode ter decorrido das condições ambientais desfavoráveis, notadamente a baixa precipitação, no período seco do ano.

A eficiência de pastejo, ou seja, a proporção de lâmina foliar verde acumulada consumida pelos animais (Hodgson, 1979) diferiu ( $\mathrm{P}=0,0122)$ entre os genótipos (Tabela 5). Os genótipos CE 08 A.D., Elefante B e HV-241 apresentaram maior eficiência de pastejo em comparação ao Hexaplóide, enquanto o Venezuela não diferiu dos demais.

A alta eficiência de pastejo no HV-241 decorre do baixo acúmulo de lâmina foliar verde durante o período de descanso da pastagem, da alta pressão de pastejo $(55 \mathrm{~kg}$ de PV/100 kg de lâmina foliar total) e das baixas perdas de lâmina foliar pelo pastejo. Apesar da alta eficiência de pastejo no HV-241, a quantidade de lâmina foliar verde aproveitada pelos animais foi muito menor que no CE08 A.D. e no Elefante B, sugerindo que os animais consumiram maior quantidade de lâminas foliares senescentes ou do suplemento. A baixa massa de lâmina foliar verde pré-pastejo e o baixo acúmulo de lâminas foliares verdes no HV-241 sugerem que este genótipo foi mais afetado pelos efeitos do período seco e do pastejo.

O Hexaplóide, híbrido do capim-elefante com milheto, cujo genoma foi duplicado, mesmo sob alta pressão de pastejo (55 kg de PV/100 kg de lâmina foliar total), apresentou baixa eficiência de pastejo, possivelmente em virtude das altas perdas de lâmina foliar durante o pastejo. Esse resultado sugere que as características estruturais e morfológicas, notadamente a baixa densidade de lâmina foliar verde pré-pastejo e a alta proporção de material morto na biomassa aérea deste genótipo (Cunha, 2006), dificultaram a apreensão das lâminas foliares verdes acumuladas. Assim, a grande quantidade de lâmina foliar verde residual pode ter comprometido sua qualidade, como resultado das perdas por senescência e acúmulo de material morto. De acordo com Teixeira et al. (1999), a massa de forragem após o pastejo deve ser a mínima necessária para permitir rebrota vigorosa e perenidade da pastagem, porém, sem comprometer o desempenho animal por limitações na qualidade da forragem disponível.
Tabela 5 - Acúmulo e eficiência de pastejo de lâmina foliar verde em genótipos de Pennisetum $s p$.

Table 5- Green leaf blade accumulation and grazing efficiency in Pennisetum sp. genotypes

\begin{tabular}{lcc}
\hline $\begin{array}{l}\text { Genótipo } \\
\text { Genotype }\end{array}$ & $\begin{array}{c}\text { Acúmulo de lâmina } \\
\text { foliar verde } \\
\text { Green leaf blade } \\
\text { accumulation }\end{array}$ & $\begin{array}{c}\text { Eficiência de pastejo } \\
\text { Grazing efficiency }\end{array}$ \\
\cline { 2 - 3 } & $\begin{array}{c}\text { kg de MS/ha/44 dias } \\
k g \text { DM/ha/44 days }\end{array}$ & $\begin{array}{c}\text { \% do acúmulo de } \\
\text { lâmina foliar verde \% } \\
\text { Green leaf blade accumulation }\end{array}$ \\
\hline CE 08 A.D. & $666 \mathrm{a}$ & $80 \mathrm{a}$ \\
Venezuela & $448 \mathrm{ab}$ & $59 \mathrm{ab}$ \\
HV-241 & $155 \mathrm{~b}$ & $100 \mathrm{a}$ \\
Elefante B & $642 \mathrm{a}$ & $81 \mathrm{a}$ \\
Hexaplóide & $540 \mathrm{ab}$ & $36 \mathrm{~b}$ \\
Média & 490 & 71 \\
Mean & & 18 \\
CV, \% & 37 & \\
\hline
\end{tabular}

Médias seguidas de letras minúsculas diferentes na coluna diferem $(\mathrm{P}<0,05)$ pelo teste Tukey.

Means followed by different lower case letters in the column differ $(P<0.05)$ by Tukey test.

$\mathrm{Na}$ Venezuela, embora as perdas de lâmina foliar durante o pastejo tenham sido altas, a eficiência de pastejo foi intermediária. A alta eficiência de pastejo nos genótipos CE 08 A.D. e Elefante B pode ser atribuída às baixas perdas de lâmina foliar pelo pastejo associadas à estrutura e morfologia desses genótipos (Cunha, 2006). Segundo Pedreira et al. (2005), a morfologia e o padrão de perfilhamento podem explicar, em parte, a alta eficiência de pastejo no capim-elefante cv. Guaçu.

Os resultados deste trabalho sugerem que o manejo de genótipos de Pennisetum sp. sob pastejo no período seco do ano deve ser diferenciado, tendo em vista as diferenças entre os genótipos quanto aos fatores relacionados à eficiência de pastejo.Ressalta-se, no entanto, que a conversão do tecido foliar produzido e acumulado em produto animal depende, além da eficiência de pastejo, também da composição química e da digestibilidade das lâminas foliares desses genótipos.

Considerando a resposta plástica dos genótipos aopastejo e às variações climáticas, trabalhos com maior período de avaliação devem ser realizados visando à maior segurança na seleção de genótipos de capim-elefante e de seus híbridos com milheto para utilização sob pastejo.

\section{Conclusões}

A massa de lâmina foliar verde diminuiu mais acentuadamente até o segundo dia de pastejo. As perdas de lâmina foliar total, no entanto, foram maiores no 20 e 30 dias de pastejo. 
As perdas de lâmina foliar total e a eficiência de pastejo variaram entre os genótipos de Pennisetum sp.

Os genótipos CE 08 A.D. e Elefante B apresentam potencial para serem utilizados em sistema de lotação rotacionada na Zona da Mata pernambucana.

\section{Literatura Citada}

AROEIRA, L.J.M.; LOPES, F.C.F.; DERESZ, F. et al. Pasture availability and dry matter intake of lactating crossbred cows grazing elephant grass (Pennisetum purpureum Schum.). Animal Feed Science and Technology, v.78, n.3, p.313-324, 1999.

BRÂNCIO, P.A.; EUCLIDES, V.P.B.; NASCIMENTO JR., D. et al. Avaliação de três cultivares de Panicum maximum Jacq. sob pastejo: disponibilidade de forragem, altura do resíduo pós-pastejo e participação de folhas, colmos e material morto. Revista Brasileira de Zootecnia, v.32, n.1, p.55-63, 2003.

CARVALHO, C.A.B.; SILVA, S.C.; SBRISSIA, A.F. et al. Demografia do perfilhamento e acúmulo de matéria seca em Coastcross submetido a pastejo. Pesquisa Agropecuária Brasileira, v.36, n.3, p.567-575, 2001.

CeCATO, U.; CASTRO, C.R.C.; CANTO, M.W. et al. Perdas de forragem em capim-Tanzânia (Panicum maximum Jacq. cv. Tanzânia-1) manejado sob diferentes alturas sob pastejo. Revista Brasileira de Zootecnia, v.30, n.2, p.295-301, 2001.

CUNHA, M.V. Características estruturais e morfológicas relacionadas à eficiência de pastejo em Pennisetum sp. no período de seca. Recife: Universidade Federal Rural de Pernambuco, 2006. 104p. Dissertação (Mestrado em Produção Animal) - Universidade Federal Rural de Pernambuco, 2006.

DAHER, R.F.; PEREIRA, M.G.; PEREIRA, A.V. et al. Genetic divergence among elephantgrass cultivars assessed by rapd markers in composit samples. Scientia Agricola, v.59, n.4, p.623-627, 2002 .

DERESZ, F. Influência do período de descanso da pastagem de capimelefante na produção de leite de vacas mestiças Holandês $x$ Zebu. Revista Brasileira de Zootecnia, v.30, n.2, p.461469, 2001.

DILlY, O.; BLOEM, J.; VOS, A. et al. Bacterial diversity in agricultural soils during litter decomposition. Applied and Environmental Microbiology, v.70, n.1, p.468-474, 2004.

ENCARNAÇÃO, C.R.F. Observações meteorológicas e tipos climáticos das unidades e campos experimentais da Empresa IPA. Recife: Empresa Pernambucana de Pesquisa Agropecuária, 1980. 115p.

ERBESDOBLER, E.D.; FONTES, C.A.A.; QUEIROZ, D.S. et al. Avaliação do consumo e ganho de peso de novilhos em pastejo rotacionado de capim-elefante (Pennisetum purpureum, Schum.) cv. Napier, na estação chuvosa. Revista Brasileira de Zootecnia, v.31, n.5, p.2123-2128, 2002.

FREITAS, E.V.; LIRA, M.A.; DUBEUX JR., J.C.B. et al. Características produtivas e qualitativas de clones de capimelefante (Pennisetum purpureum Schum.) avaliados sob pastejo na Zona da Mata de Pernambuco. Acta Scientiarum, v.26, n.2, p.251-257, 2004.

HILLESHEIM, A. Manejo do gênero Pennisetum sob pastejo. In: SIMPÓSIO SOBRE MANEJO DA PASTAGEM, 9., 1998, Piracicaba. Anais... Piracicaba: Fundação de Estudos Agrários Luiz de Queiroz, 1988. p.37-68.

HODGSON, J. Nomenclature and definitions in grazing studies. Grass and Forage Science, v.34, n.1, p.11-18, 1979.

LEMAIRE, G. The physiology of grass growth under grazing: tissue turn-over. In: SIMPÓSIO INTERNACIONAL SOBRE PRODUÇÃO ANIMAL EM PASTEJO, 1997, Viçosa, MG. Anais... Viçosa, MG: Universidade Federal de Viçosa, 1997. p.117-144.
LEMAIRE, G.; AGNUSDEI, M. Leaf tissue turnover and efficiency of herbage utilisation. In: LEMAIRE, G.; HODGSON, J.; MORAES, A. et al. (Ed.). Grassland ecophysiology and grazing ecology. Wallingford: CAB International, 2000. p.265-288.

LIMA, M.L.P.; BERCHIELLI, T.T., LEME, P.R. et al. Concentração de nitrogênio uréico plasmático (NUP) e produção de leite de vacas mestiças mantidas em gramíneas tropicais sob pastejo rotacionado. Revista Brasileira de Zootecnia, v.33, n.6, p.1616-1626, 2004.

LOPES, F.C.F.; DERESZ, F.; RODRIGUEZ, N.M. et al. Disponibilidade e perdas de matéria seca em pastagem de capimelefante (Pennisetum purpureum, Schumack) submetida a diferentes períodos de descanso. Arquivo Brasileiro de Medicina Veterinária e Zootecnia, v.55, n.4, p.454-460, 2003.

MELLO, A.C.L.; LIRA, M.A.; DUBEUX JR., J.C.B. et al. Caracterização e seleção de clones de capim-elefante (Pennisetum purpureum Schum.) na Zona da Mata de Pernambuco. Revista Brasileira de Zootecnia, v.31, n.1, p.30-42, 2002 .

MOTT, G.O. Relationship of available forage and animal performance in tropical grazing systems. In: FORAGE AND GRASSLAND CONFERENCE, 1984, Houston.Proceedings... Lexington: American Forage and Grassland Council, 1984. p. 373-377.

NEUMANN, M.; RESTle, J.; ALVES FILHO, D.C. et al. Desempenho de bezerros e bezerras de corte em pastagem de capim elefante (Pennisetum purpureum, Schum.) associado a diferentes níveis de suplementação. Ciencia Rural, v.35, n.1, p.157-163, 2005.

PACIULLO, D.S.C.; DERESZ, F.; AROEIRA, L.J.M. et al. Morfogênese e acúmulo de biomassa foliar em pastagem de capim-elefante avaliada em diferentes épocas do ano.Pesquisa Agropecuária Brasileira, v.38, n.7, p.881-887, 2003.

PARSONS, A.J.; JOHNSON, L.R.; WILLIAMS, J.H.H. Leaf age structure and canopy photosynthesis, leaf death and the average rate of growth in a rotationally grazed sward. Grass and Forage Science, v.43, n.1, p.15-27, 1988.

PEDREIRA, C.G.S.; ROSSETO, F.A.A.; SILVA, S.C. et al. Forage yield and grazing efficiency on rotationally stocked pastures of 'Tanzania-1' guineagrass and 'Guaçu' elephantgrass. Scientia Agricola, v.62, n.5, p.433-439, 2005.

PEREIRA, A.V.; MARTINS, C.E.; CRUZ FILHO, A.B. et al. Pioneiro - nova cultivar de capim-elefante para pastejo. In: REUNIÃO ANUAL DA SOCIEDADE BRASILEIRA DE ZOOTECNIA, 34., 1997, Juiz de Fora. Anais... Juiz de Fora: Sociedade Brasileira de Zootecnia, 1997. p.102-104.

QUADROS, D.G.; RODRIGUES, L.R.A.; FAVORETTO, V. et al. Componentes da produção de forragem em pastagens dos capins tanzânia e mombaça adubadas com quatro doses de NPK. Revista Brasileira de Zootecnia, v.31, n.3, supl, p.13331342, 2002.

RESTLE, J.; ROSO, C.; AITA, V. et al. Produção animal em pastagem com gramíneas de estação quente. Revista Brasileira de Zootecnia, v.31, n.3, p.1491-1500, 2002.

SANTOS, A.L.; LIMA, M.L.P.; BERCHIELLI, T.T. et al. Efeito do dia de ocupação sobre a produção leiteira de vacas mestiças em pastejo rotacionado de forrageiras tropicais. Revista Brasileira de Zootecnia, v.34, n.3, p.1051-1059, 2005.

SANTOS, P.M.; BALSALOBRE, M.A.A.; CORSI, M. Características morfogenéticas e taxa de acúmulo de forragem do capimmombaça submetido a três intervalos de pastejo. Revista Brasileira de Zootecnia, v.33, n.4, p.843-851, 2004.

STATISTICAL ANALYSIS SYSTEM - SAS. SAS/STAT User's guide. Version 8. Cary: 1999. 1464p.

SOLLENBERGER, L.E.; MOORE, J.E.; ALLEN, V.G. et al. Reporting forage allowance in grazing experiments. Crop Science, v.45, n.3, p.896-900, 2005. 
STUTH, J.W.; KIRBY, D.R.; CHMIELEWSKI, R.E. Effect of herbage allowance on the efficiency of defoliation by the grazing animal. Grass and Forage Science, v.36, n.1, p.9-15, 1981.

SUDENE. Dados pluviométricos mensais do Nordeste-Estado de Pernambuco. Recife, 1990. p.78-79 (BRASIL, SUDENE. Pluviometria, 6).

TEIXEIRA, E.I.; MATTOS, W.R.S.; CAMARGO, A.C. et al. Avaliação de produção e utilização de uma pastagem de capim tobiatã (Panicum maximum cv. Tobiatã) sob pastejo rotacionado. Scientia Agricola, v.56, n.2, 1999, p.349-355.
VALLE, C.B.; SOUZA, F.H.D. Construindo novas cultivares de gramíneas forrageiras para os cerrados brasileiros. In: REUNIÃO ANUAL DA SOCIEDADE BRASILEIRA DE ZOOTECNIA, 32., 1995, Brasília. Anais... Brasília: Sociedade Brasileira de Zootecnia, 1995. p.3-7. 